\title{
INVESTIGATIONS ON THE DEGREE OF BLEACHING OF QUARTZ OSL SIGNALS USING MODERN AEOLIAN DUST FROM WESTERN LOESS PLATEAU, CHINA
}

\author{
TIANLAI FAN ${ }^{1,2}$, YUXIN FAN ${ }^{1,2}$, HUI ZHAO ${ }^{3}$, FAHU CHEN ${ }^{1}$ and ZHONGPING LAI ${ }^{4}$ \\ ${ }^{1}$ MOE Key Laboratory of West China's Environmental Systems, Lanzhou University, \\ Lanzhou 730000, China \\ ${ }^{2}$ Key Laboratory of Mineral Resources in Western China (Gansu Province), Lanzhou University, \\ Lanzhou 730000, China \\ ${ }^{3}$ Key Laboratory of Desert and Desertification, Cold and Arid Regions Environmental and Engineering Research Institute, Chinese \\ Academy of Sciences, Lanzhou 730000, China \\ ${ }^{4}$ State Key laboratory of Cryospheric Sciences, Cold and Arid Regions Environmental and Engineering Research Institute, Chinese \\ Academy of Sciences, Lanzhou 730000, China
}

\begin{abstract}
Optically Stimulated Luminescence signal of quartz extracted from modern aeolian dust with known maximum age (about decades) was analyzed in terms of degree of bleaching. The results of dose recovery tests show that the modified double single-aliquot regenerative-dose protocol with the early background subtraction is robust for dating these modern dusts using small aliquots. Bleaching of these dusts is discussed based on the distribution of $D_{e}$ values in histograms, scatter plots of $D_{e}$ versus sensitivity corrected natural OSL signal and comparison between measured $\mathrm{D}_{\mathrm{e}}$ and expected $\mathrm{D}_{\mathrm{e}}$. The results indicate that most dusts were completely bleached but some dusts were not completely bleached. For those incompletely bleached dusts in Lanzhou area, the maximum OSL age overestimation is up to $\sim 1 \mathrm{ka}$, which might be caused by fast deposition accompanied by heavy sand/dust storms. The research suggests that cautions should be given to OSL ages younger than $1 \mathrm{ka}$ in the western China close to deserts.
\end{abstract}

Keywords: Incomplete bleaching, Quartz, Modern dust, Chinese Loess Plateau.

\section{INTRODUCTION}

Optically stimulated luminescence (OSL) dating is increasingly used to date late Quaternary sediments on millennial, centurial and even decadal scale depositional events (Madsen and Murray, 2009; Pietsch, 2009). For young sediments, however, OSL dating is inherently problematic and may yield seriously overestimated OSL

Corresponding author: Y. Fan

e-mail: yxfan@1zu.edu.cn ages mainly due to potential incomplete bleaching, which has been observed in fluvial sediments (Olley et al., 1998; 1999; Stokes et al., 2001; Jain et al., 2004; Fiebig and Preusser, 2007; Hu et al., 2010), hurricane sediments (Huntley and Clague, 1996; Madsen and Murray, 2009), tsunami deposits (Brill et al., 2012) and glaciofluvial or deltaic sediments (Alexanderson and Murray, 2007; 2012; Fuchs and Owen, 2008; Gemmell et al., 2007; Shen and Mauz, 2012). Generally, aeolian sediment such as loess is an ideal material for OSL dating, because 
quartz grains should have experienced long time of exposure to sun lighting during long distance transportation before deposition (Stokes et al., 2004; Roberts, 2008). However, incomplete optical bleaching was also found in young aeolian sediments (Goble et al., 2004; Costas et al., 2012). Considering that incomplete bleaching can lead to significantly overestimated ages especially for young aeolian sediments, the degree of bleaching of modern dusts from western Chinese Loess Plateau is investigated in order to provide further insights into OSL dating.

\section{SAMPLES AND FACILITIES}

Deserts of northern China adjacent to the Loess Plateau are regarded as the dominant source of dusts (Zhang, 2007). Dust/sand storms occur frequently and widely during spring in northern China (Qian et al., 2004), providing enough and suitable dust samples to study bleaching characteristics of modern aeolian sediments. High buildings are perfect places for dust deposition. Most modern aeolian dust samples were collected from surfaces or roofs of high buildings situated at the bank of the Yellow River with one from the top of Jiuzhoutai mountain in Lanzhou, western Chinese Loess Plateau which is around $200 \mathrm{~km}$ south to the Tengger Desert (Fig. 1).

All dust samples were collected only when sunlight was subtle enough to avoid bleaching during sampling. The samples were brushed quickly into light-tight plastic vials. Documents of these ten buildings serve as the independent known maximum age (5-25 a) of these dust samples. The thickness of the dust layer varies between 1-2 $\mathrm{mm}$. Considering that the grains maybe have experienced reworking or deposit very recently, the history of these modern dusts should not be older than the independent control if they were completely bleached before last deposition.

The grain size of modern dusts was analyzed to decide which fraction is dominant and appropriate for $D_{e}$ measurement. The typical mode size of these dust samples (e.g. TSG, Fig. 2), $\sim 26 \mu \mathrm{m}$, is similar to that of loess in Lanzhou and adjacent area (Sun et al., 2000), and more than $80 \%$ of the grains fall in the 11-63 $\mu \mathrm{m}$ size window while $\sim 12 \%$ and $\sim 8 \%$ are $<11 \mu \mathrm{m}$ and $>63 \mu \mathrm{m}$ respectively (Fig. 2), suggesting that the 11-63 $\mu \mathrm{m}$ fraction is dominant in these samples. Only from sample TSG and HH$5 \mathrm{D}$, enough amount of $38-63 \mu \mathrm{m}$ fraction was obtained.

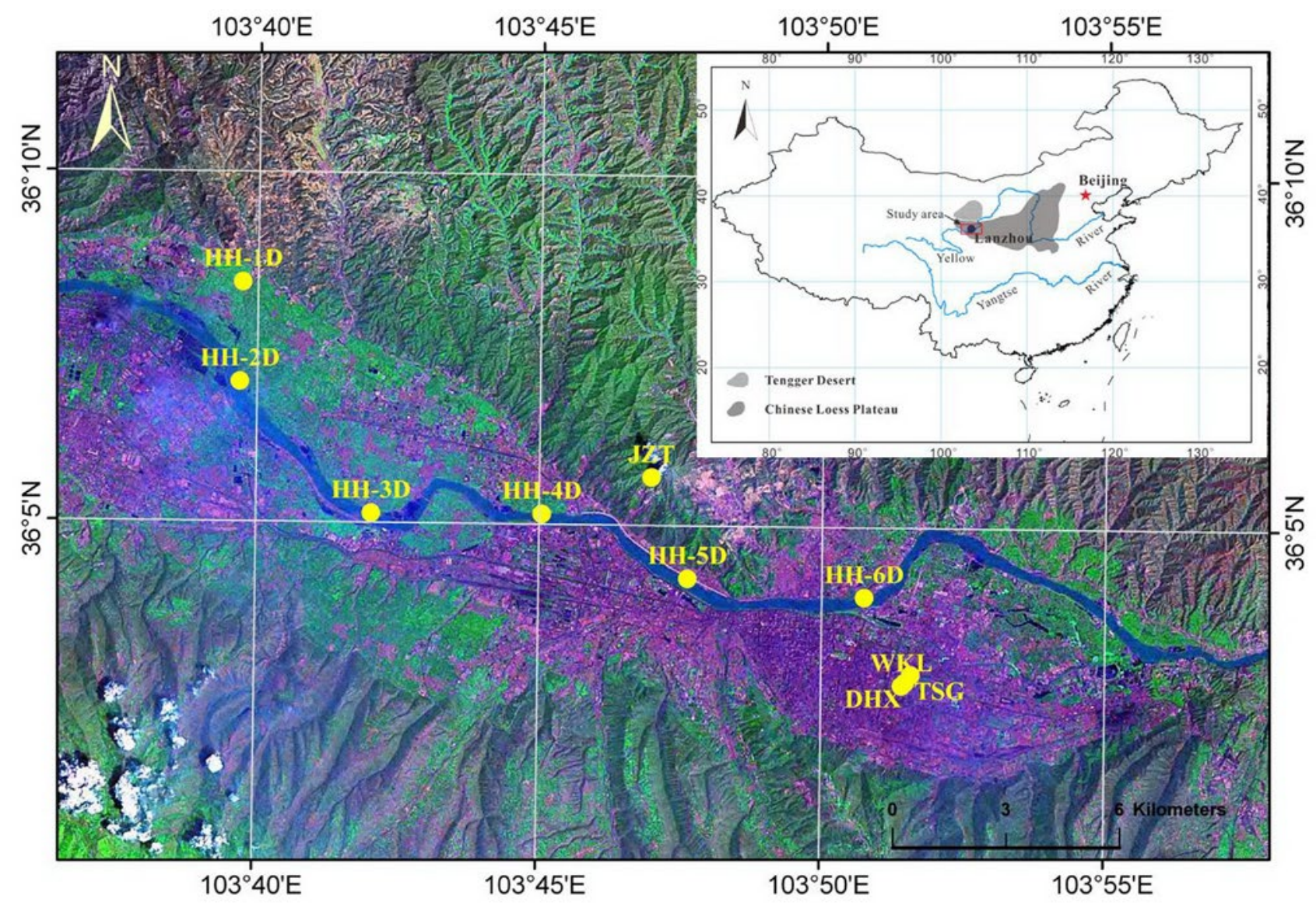

Fig. 1. Map of the study area and location of sampling sites. 


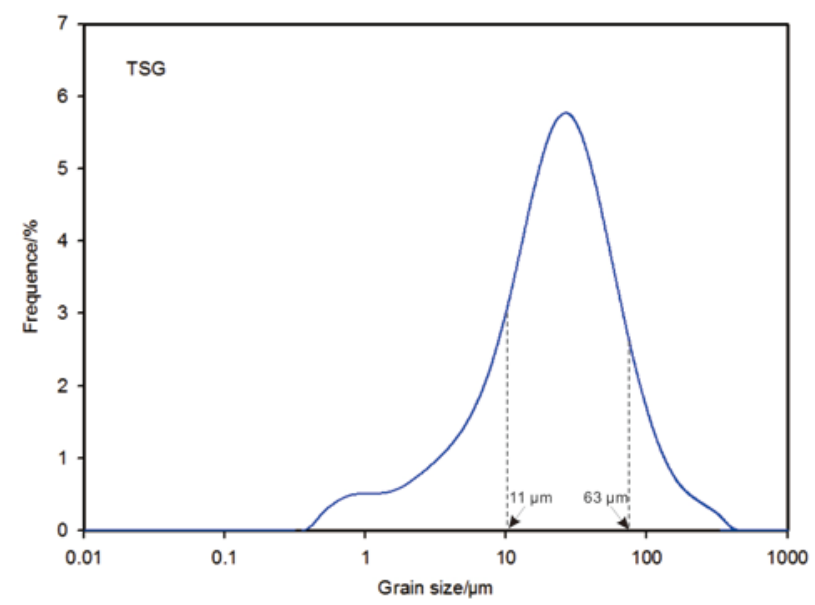

Fig. 2. Frequency distribution of grain size for a typical dust sample (TSG). Note that the horizontal axis is expressed in logarithmic form. Two dotted lines illustrate the location of the $11 \mu \mathrm{m}$ and $63 \mu \mathrm{m}$ on horizontal axis respectively.

Consequently, OSL signal of the 11-63 $\mu \mathrm{m}$ quartz fraction was used for testing the bleaching property of these dusts based on the assumption that no natural OSL signal above background from quartz fractions should be expected in well bleached modern dust. Routine sample preparation procedure was used to separate quartz from loess to extract 11-63 $\mu \mathrm{m}$ quartz fraction (Berger et al., 1980; Lu et al., 1988; Forman, 1991). Under subtle red light in the darkroom of the laboratory, the dust samples were soaked in $10 \% \mathrm{H}_{2} \mathrm{O}_{2}$ and $30 \% \mathrm{HCl}$ for a week to remove any carbonate and organic materials. Then the samples were refined to 11-63 $\mu \mathrm{m}$ fraction (including 38-63 $\mu \mathrm{m}$ fraction of sample TSG and HH-5D) using sedimentation procedure based on Stokes's Law. The polymineral fraction was then etched in $10 \% \mathrm{H}_{2} \mathrm{SiF}_{6}$ with ultrasonic bathing for three days to remove feldspar components. And then, the 11-63 $\mu \mathrm{m}$ quartz fraction was treated with $10 \% \mathrm{HCl}$ to remove any contaminating fluorides, and rinsed with deionized water repeatedly until it reached neutral $\mathrm{pH}$. Subsequently, the purity was checked by depletion of natural infrared stimulated luminescence (IRSL) signal, and those samples that show existence of bright IRSL signal were etched and rinsed again until there was no apparent IRSL signal above background.

A great number of previous studies have demonstrated that small aliquots measurement can identify sediments containing grains with different $\mathrm{D}_{\mathrm{e}}$ values (Olley et al., 1999; Tooth et al., 2007; Duller, 2008). In this study, small aliquots were made by mounting 11-63 $\mu \mathrm{m}$ quartz fraction on the $1 \mathrm{~mm}$ diameter centre part of stainless steel discs using silicone oil. In the luminescence laboratory of the key laboratory of western China's environmental systems (Ministry of Education) of Lanzhou University, OSL signals were measured on an automated Risø TL/OSL-DA-20 reader equipped with a ${ }^{90} \mathrm{Sr} /{ }^{90} \mathrm{Y}$ beta source, using $470 \mathrm{~nm}$ blue diodes with a power at the sample position of $\sim 50 \mathrm{~mW} / \mathrm{cm}^{-2}$, and the IR diodes emitted at a wavelength of $870 \mathrm{~nm}$ and power of $\sim 135 \mathrm{~mW} / \mathrm{cm}^{-2}$. A $7.5 \mathrm{~mm}$ Hoya U-340 detection filter was used (Thomsen et al., 2008). The average of radioactive intensity for the $11-38 \mu \mathrm{m}$ and 38-63 $\mu \mathrm{m}$ fraction using known $\mathrm{D}_{\mathrm{e}}$ values standard samples was taken as the approximate radioactive intensity for the 11-63 $\mu \mathrm{m}$ fraction.

\section{METHODS}

\section{Modified double singe-aliquot regenerative-dose (SAR) protocol}

In order to eliminate the potential contribution of IRSL signal from feldspar inclusions hosted in quartz crystals, the modified double-SAR protocol (Banerjee et al., 2001; Roberts and Wintle, 2001) listed in Table 1 was used to measure the OSL signal from quartz fractions. In this protocol, preheat at $160-260^{\circ} \mathrm{C}$ was applied before IRSL measurement at $50^{\circ} \mathrm{C}$ for 40 seconds which was followed by OSL measurement at $125^{\circ} \mathrm{C}$ for $40 \mathrm{sec}-$ onds. Then $180^{\circ} \mathrm{C}$ cut-heat was conducted before measurements of IRSL signal and OSL signal to the test dose. Finally, a $280^{\circ} \mathrm{C}$ illumination was carried out before the next regenerative dose irradiation (Murray and Wintle, 2003; Wintle and Murray, 2006). Due to the low intensity of the signals (as illustrated in Fig. 3a and 3b), a relatively large test dose of 0.75 Gy was applied to have an acceptable counting statistics. The protocol was repeated for five cycles with regenerative doses of $0.75 \mathrm{~Gy}$, $1.50 \mathrm{~Gy}, 2.25 \mathrm{~Gy}, 0$ and 0.75 Gy respectively. Only aliquots that satisfied the following criteria (namely qualified aliquots in the following text) were used in statistics and discussions of $\mathrm{D}_{e}$ distribution: (1) there is no visible IRSL decay above background; (2) the recycling ratio is

Table 1. The modified double-SAR protocol used in this study.

\begin{tabular}{cll}
\hline Step & Treatment & Observed \\
\hline 1 & Regenerative dose & $\mathrm{Di}_{\mathrm{i}}\left(\mathrm{i}=0 \ldots . . .5 ; \mathrm{D}_{0}=0\right)$ \\
\hline 2 & Preheat $(160-260)^{\circ} \mathrm{C}$ for $10 \mathrm{~s}$ & $\begin{array}{l}\text { Determined by result } \\
\text { of dose recovery test }\end{array}$ \\
\hline 3 & Infrared Optically stimulate for $40 \mathrm{~s}$ at $50^{\circ} \mathrm{C}$ \\
\hline 4 & Blue Optically stimulate for $40 \mathrm{~s}$ at $125^{\circ} \mathrm{C}$ & $\mathrm{L}_{\mathrm{i}}$ \\
\hline 5 & Test dose & $\mathrm{D}_{\mathrm{t}}$ \\
\hline 6 & $\mathrm{TL}$ at $180^{\circ} \mathrm{C}$ & \\
\hline 7 & Infrared Optically stimulate for $40 \mathrm{~s}$ at $50^{\circ} \mathrm{C}$ \\
\hline 8 & Blue Optically stimulate for $40 \mathrm{~s}$ at $125^{\circ} \mathrm{C}$ & $\mathrm{T}_{\mathrm{i}}$ \\
\hline 9 & Illumination at $280^{\circ} \mathrm{C}$ for $40 \mathrm{~s}$ & \\
\hline 10 & Return to step 1 & \\
\hline
\end{tabular}

Notes: The sequence is repeated for five regenerative doses including a zero Gy dose and a repeated regenerative dose. The five regenerative doses are $0.75 \mathrm{~Gy}, 1.5 \mathrm{~Gy}, 2.25 \mathrm{~Gy}, 0 \mathrm{~Gy}$ and $0.75 \mathrm{~Gy}$, respectively. For the natural dose, $i=0$ and $D_{0}=0$. The test dose for all samples is $0.75 \mathrm{~Gy}$. The step 9 of illumination at elevated temperature >preheat temperature is from Murray and Wintle (2003). 

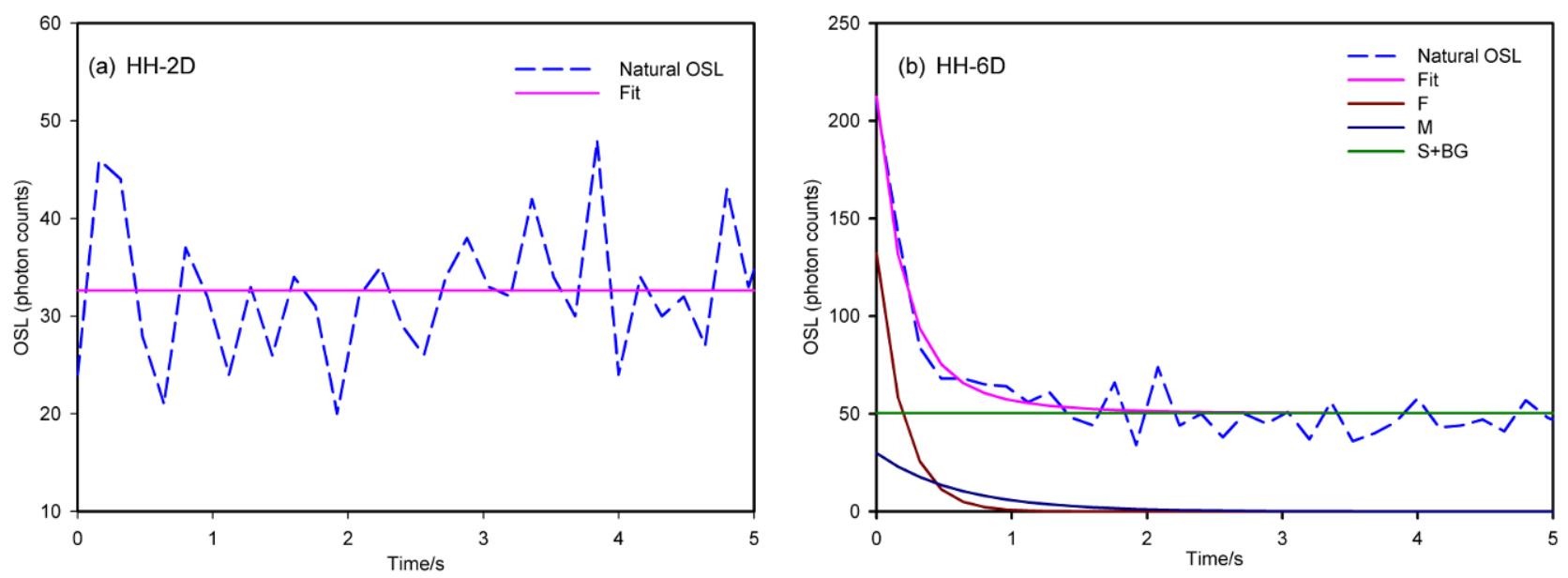

Fig. 3. Natural OSL decay curves and the curve fitting results for representative aliquots of sample $H H-2 D(a)$ and $H H-6 D(b)$.

within $20 \%$ of unity (in order to increase number of aliquots involved); (3) insignificant recuperation $(<5 \%)$, which is adopted to reduce effect of thermal transfer to a negligible level and make the protocol more stringent, though $10 \%$ or more was used in the similar study (Madsen and Murray, 2009).

Prior to measurements of OSL signals, dose recovery tests were performed to select suitable preheat and stimulation temperatures (Wintle and Murray, 2006) as well as to test the validity of a modified double-SAR protocol for each sample. Before the dose recovery test, the OSL signal of quartz from each sample was reset by illuminating aliquots under strong sunlight for six hours to empty previous OSL signals. Then a 1.5 Gy dose was given to the bleached aliquots by irradiation through a built-in beta source. Three aliquots were prepared for each preheat temperature. By using the modified double SAR protocol, we obtained the measured doses from the irradiated aliquots and at least one aliquot was used to calculate the dose recovery ratio (=Measured/Given dose ratio) at different preheat temperatures. Only the preheat temperature at which both the dose recovery ratio and recycling ratios were within $10 \%$ of unity and where recuperation was smaller than $5 \%$ were employed in the modified double SAR protocol to measure OSL signal of quartz fractions. For example, as illustrated in Fig. 4, the dose recovery test results indicate that preheat at $240^{\circ} \mathrm{C}$ is suitable for dust sample HH-3D.

\section{Isolation of the fast-component-dominated OSL signal}

Only the fast component is the most suitable for optical dating by using SAR protocol because fast component is the most stable and easily bleached (Wintle and Murray, 2006). The fast component was isolated by using many methods including LM-OSL measurement and curve fitting method (e.g. Bulur, 1996; Bailey et al., 1997; Singarayer and Bailey, 2004; Ballarini et al., 2007; Wallinga et al., 2008; Cunningham and Willinga, 2010).
In this study, we isolated the fast component signal by using the early background (EBG) subtraction method (Ballarini et al., 2007; Cunningham and Wallinga, 2009; 2010). Since the selection of integration limit significantly affects the contribution of fast component to $D_{e}$ values (Cunningham and Wallinga, 2009; 2010), the optimal integration limit of OSL signal and background is selected through fitting method only when the contribution of fast component is maximized. In this experiment, the signal during the first $0.16 \mathrm{~s}$ was integrated as the OSL signal with the subsequent $0.64 \mathrm{~s}(0.16-0.80 \mathrm{~s})$ OSL signal immediately followed as the background as a result of optimal integration limit.

\section{RESULTS}

In the following sections, we focus on detection of incomplete bleaching based on the decay characteristics of OSL signal, $\mathrm{D}_{\mathrm{e}}$ distribution and comparison of measured $D_{e}$ with the known $D_{e}$ values of dusts.

\section{Unwanted decay}

A modern sample may be considered to have been partially bleached if its fast and/or medium components have not been fully reset (Singarayer et al., 2005). As illustrated in Fig. 3a, the absence of natural OSL signal (including fast component) as well as recuperation for sample HH-2D except a constant background, indicates that the previous natural OSL signals (both fast and medium component) have been completely bleached before last deposition and no decay of natural OSL signal should be expected for these fully reset samples. Samples such as HH-1D have the similar decay as sample HH-2D, indicating they are completely bleached. However, significant decay is observed from its natural OSL signal for sample HH-6D, and three components (fast, medium and slow plus background) were successfully isolated (Fig. 3b). In addition to sample HH-6D, sample WKL also 

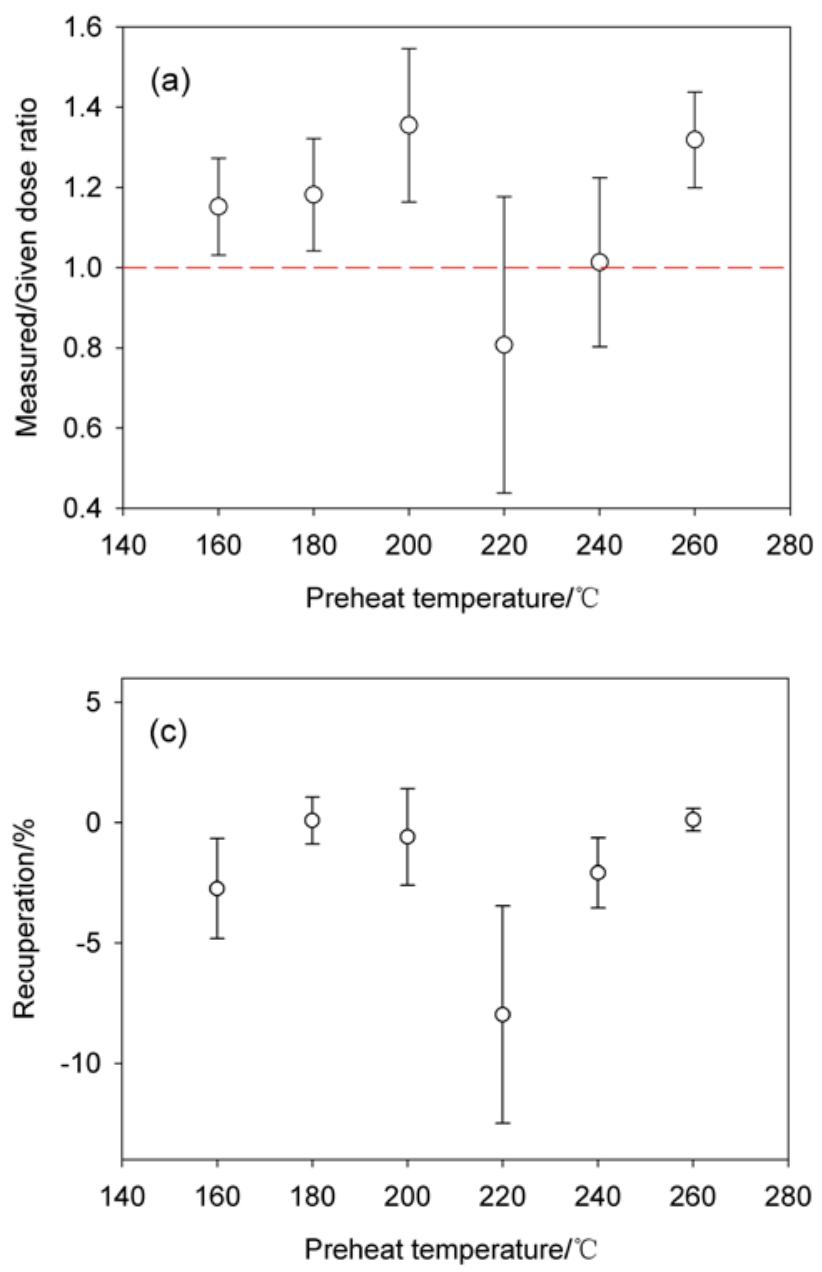

have non-negligible OSL decay. The existence of obvious decay in their natural OSL signal (including both fast and medium components) demonstrates that not only the hard-to-bleach medium decay component but also the easy-to-bleach fast decay component have not been fully reset to zero before burial.

\section{Measured $D_{\mathrm{e}}$ obviously overestimated for some dusts}

The expected $\mathrm{D}_{\mathrm{e}} \mathrm{s}$ were estimated based on the known age of buildings and the dose rate of loess from the Loess Plateau. A minimum dose rate of $\sim 3 \mathrm{~Gy} / \mathrm{ka}$ in loess (past analogue for aeolian dust in the study area) close to earth surface from different profiles is summarized from previous studies on Chinese Loess Plateau (Lai et al., 2007; Lu et al., 2007; Jiang et al., 2009). Subsequently the expected maximal $D_{e}$ values were obtained for these modern dusts (the third column of Table 2). Considering that the grains maybe have experienced reworking after deposition and/or deposit very recently (1-2 $\mathrm{mm}$ thick), the history of dusts should be not older than the independent control if they were completely bleached before last ex-

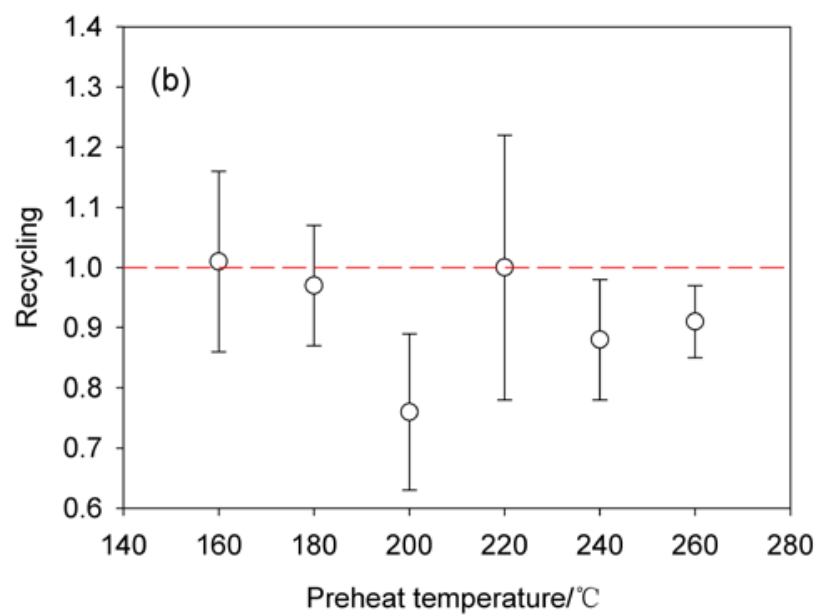

Fig. 4. Dose recovery test results of sampleHH-3D: (a) Measured/Given dose ratio; (b) Recycling ratio; (c) Recuperation at different preheat temperatures.

posure to sunlight. That is to say, the equivalent dose for the quartz on roofs should be less than the maximal value of $\sim 0.1$ Gy for sample WKL, less than 0.03 Gy for DHX and less than $0.05 \mathrm{~Gy}$ for the rest of the samples. We noticed that zero and negative $\mathrm{D}_{\mathrm{e}} \mathrm{s}$ are obtained for some modern dusts. Negative $\mathrm{D}_{\mathrm{e}} \mathrm{s}$ might be produced due to uncertainty of measurements, or poor counting statistics in the measurement of the natural OSL signal (Arnold et al., 2009). Here we think that zero and negative $D_{\mathrm{e}}$ values represent well bleached components, and therefore, zero and negative $\mathrm{D}_{\mathrm{e}} \mathrm{s}$ are also involved into statistic and calculation of $D_{e}$. Finally, the measured $D_{e}$ values of each dust sample are calculated in the forms of arithmetic mean and weighted mean $\mathrm{D}_{\mathrm{e}}$ (last two columns in Table 2) based on all qualified aliquots including zero and negative $\mathrm{D}_{\mathrm{e}} \mathrm{s}$.

It is more effective to identify incomplete bleaching by using comparison of OSL ages with independent age control than using different age models (Murray et al., 2012). In this study we followed this method to compare the measured $D_{e}$ with the expected maximal $D_{e}$ value. For 
Table 2. The comparison between expected maximum $D_{e}$ and the measured $D_{e}$ of quartz for all dust samples. The Measured/Given dose ratios and recuperation at the selected preheat temperature are also listed.

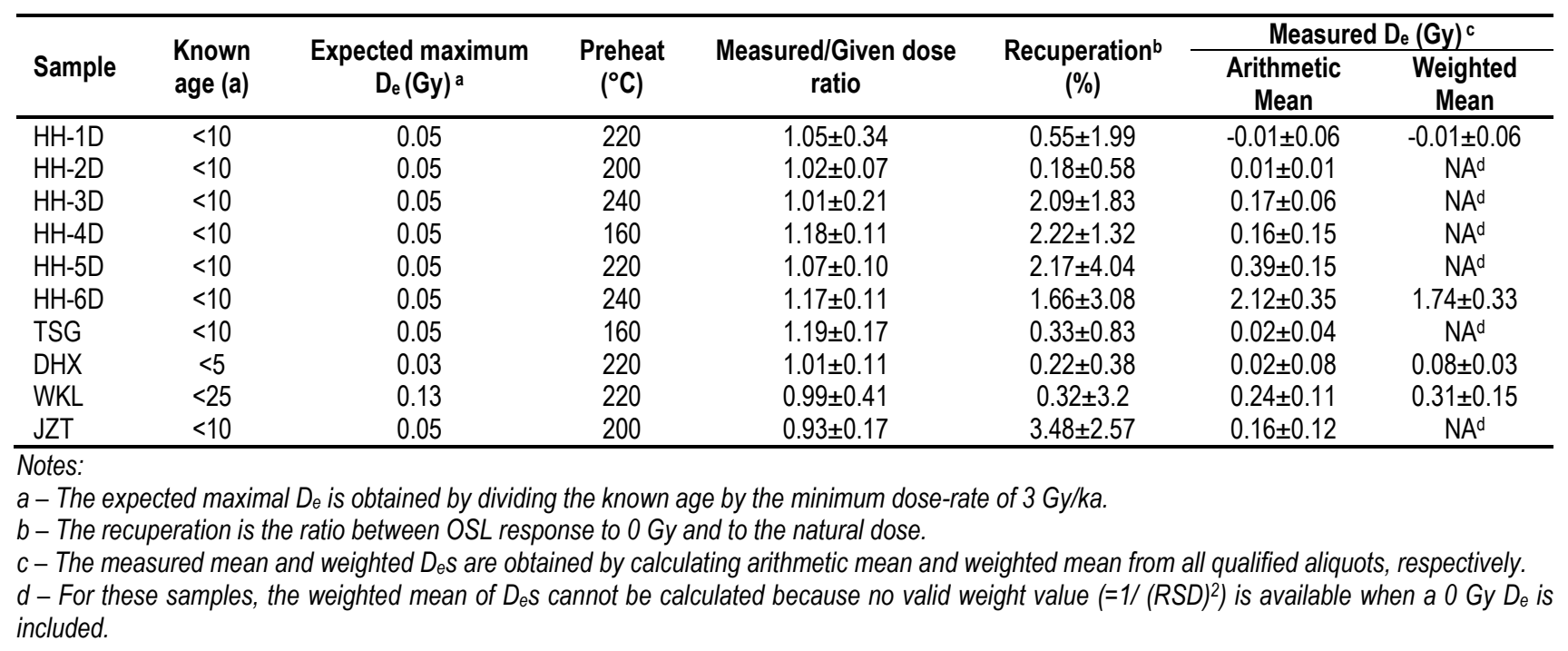

instance, the measured mean $\mathrm{D}_{\mathrm{e}} \mathrm{s}$ of samples HH-1D and HH-2D are $\sim-0.01$ Gy and 0.01 Gy respectively and very close to the expected maximal $\mathrm{D}_{\mathrm{e}}, 0.05 \mathrm{~Gy}$, indicating that most of grains of these samples should be bleached completely before last deposition. In contrast, the measured $\mathrm{D}_{\mathrm{e}}$ of samples HH-5D and HH-6D are $\sim 0.39$ Gy and $\sim 2.12$ Gy respectively and apparently larger than their expected maximum $D_{e}$, suggesting that these two samples were poorly bleached or at least some grains were bleached incompletely. Of these samples the maximal measured $\mathrm{D}_{\mathrm{e}}, \sim 3.39 \mathrm{~Gy}$, of a aliquot of sample HH-6D was obtained and significantly overestimated compared with the expected maximal $D_{e}, 0.05 \mathrm{~Gy}$. In other words, the maximal overestimated OSL age for this sample will be up to around $1 \mathrm{ka}$.

In order to exclude the potential influence of beta dose heterogeneity to the big grain size range used (11-63 $\mu \mathrm{m})$ as Armitage and Bailey (2005) noticed in their studies, we measured $D_{e}$ values of the $38-63 \mu \mathrm{m}$ from samples TSG and HH-5D and make a comparison with their $D_{e}$ values of the 11-63 $\mu \mathrm{m}$ size range. The mean $\mathrm{D}_{\mathrm{e}}$ of 38-63 $\mu \mathrm{m}$ fractions for samples TSG and HH5D are 0.13 Gy and 0.63 Gy respectively, which are almost the same as those of the 11-63 $\mu \mathrm{m}$ fraction ( $\sim 0.02$ Gy and $\sim 0.39$ Gy respectively) in magnitude. The comparison results between two different size ranges suggest that poor/incomplete bleaching still can be distinguished no matter which size range is used.

\section{$D_{\mathrm{e}}$ distribution}

Two notable and simple forms to demonstrate $\mathrm{D}_{\mathrm{e}}$ distribution are histogram and scatter plot ( $\mathrm{Li}$ and Wintle, 1992; Clarke, 1996; Galbraith and Roberts, 2012). Histograms of $D_{e}$ values are straightforward if bin size is appropriately chosen with precision of $\mathrm{D}_{\mathrm{e}}$ illustrated, alt- hough the choice of bin size is arbitrary and precision associated with each $D_{e}$ is not taken into account (Galbraith and Roberts, 2012). The other alternative, scatter plot of $D_{e}$ versus sensitivity corrected natural OSL signal, was often used to identify incomplete bleaching ( $\mathrm{Li}$ and Wintle, 1992; Clarke, 1996; Colls et al., 2001). In principle, plots of $D_{e}$ versus OSL signal intensity showing a statistically significant linear trend are indicative of either partial bleaching or grain mixing (Colls et al., 2001; Stokes et al., 2001). In order to show $\mathrm{D}_{\mathrm{e}}$ distribution visually, we used small bin of 0.02 Gy in $D_{e}$ values histogram. On top of each histogram, uncertainty of each $D_{e}$ value is also illustrated to show precision of each measurement (Fig. 5). Furthermore, we plot $D_{e}$ values versus sensitivity corrected natural OSL signal (Fig. 6). And in these figures, all $D_{e}$ values including zero and negative $\mathrm{D}_{\mathrm{e}} \mathrm{s}$ are plotted.

\section{Dispersed $D_{e}$ distribution in histogram}

Also shown in each histogram are number of qualified aliquots, number of all aliquots measured, as well as the mean $\mathrm{D}_{\mathrm{e}}$ values based on qualified aliquots. To make a visual comparison, the expected maximal $\mathrm{D}_{\mathrm{e}}$ is illustrated as blue dashed line in $\mathrm{D}_{\mathrm{e}}$ histogram in Fig. 5 and scatter plot in Fig. 6. We noticed that the natural OSL signals are generally bright, but most aliquots do not satisfy the selected criteria mentioned above and were not involved into statistics. For example, only 8 aliquots of sample HH-6D pass the criteria although 52 aliquots are measured (Fig. 5f) and most of them show relatively bright natural OSL signal.

For completely bleached samples, the measured $D_{e} s$ should be smaller than their expected maximal $\mathrm{D}_{\mathrm{e}}$. In Fig. 5, $\mathrm{D}_{\mathrm{e}}$ of some dust samples HH-1D, HH-2D, DHX and TSG etc. are narrowly distributed (e.g., Fig. 5a, 5b, 5g, 

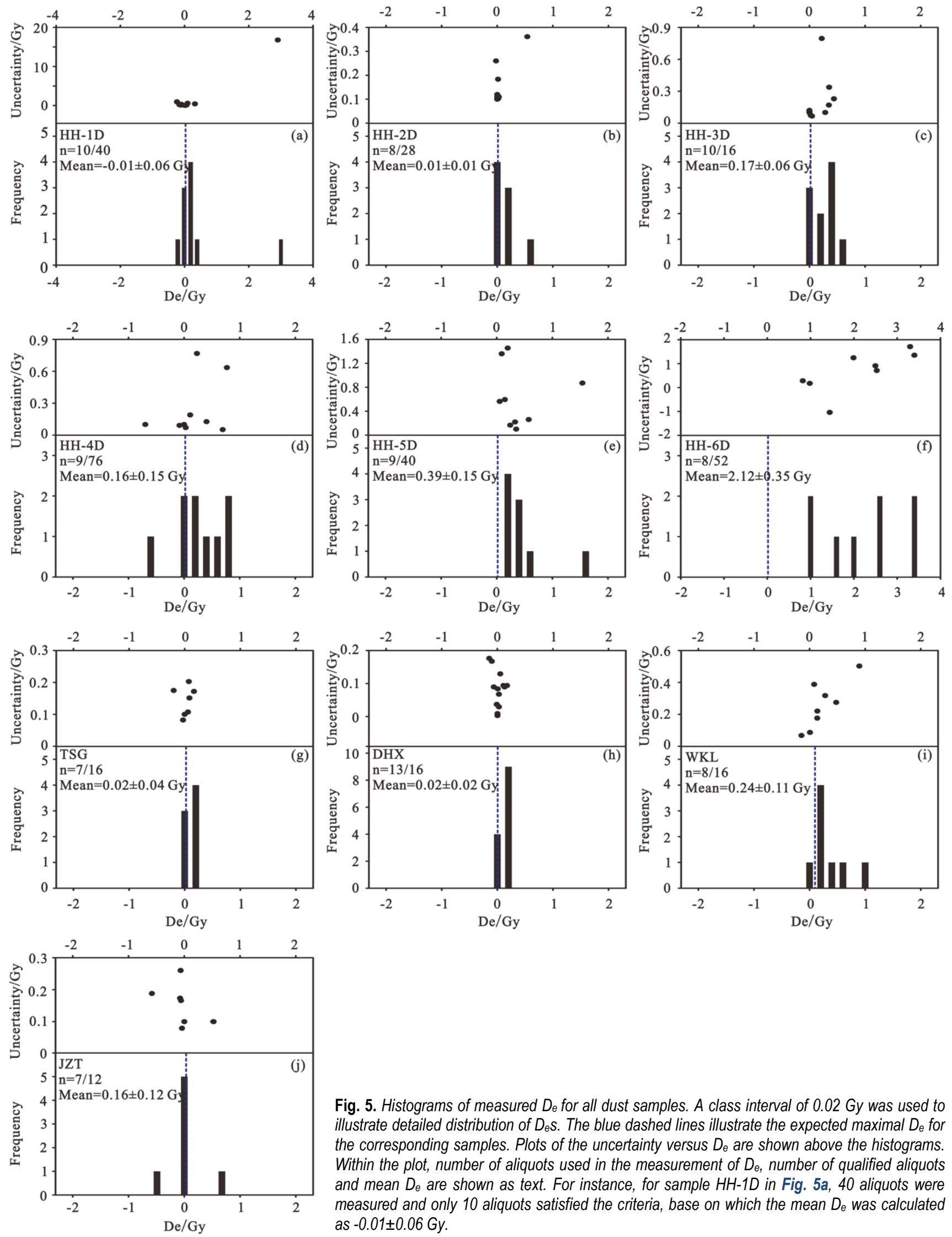

Fig. 5. Histograms of measured $D_{e}$ for all dust samples. A class interval of $0.02 \mathrm{~Gy}$ was used to illustrate detailed distribution of $D_{e} s$. The blue dashed lines illustrate the expected maximal $D_{e}$ for the corresponding samples. Plots of the uncertainty versus $D_{e}$ are shown above the histograms. Within the plot, number of aliquots used in the measurement of $D_{e}$, number of qualified aliquots and mean $D_{e}$ are shown as text. For instance, for sample HH-1D in Fig. 5a, 40 aliquots were measured and only 10 aliquots satisfied the criteria, base on which the mean $D_{e}$ was calculated as $-0.01 \pm 0.06 \mathrm{~Gy}$. 

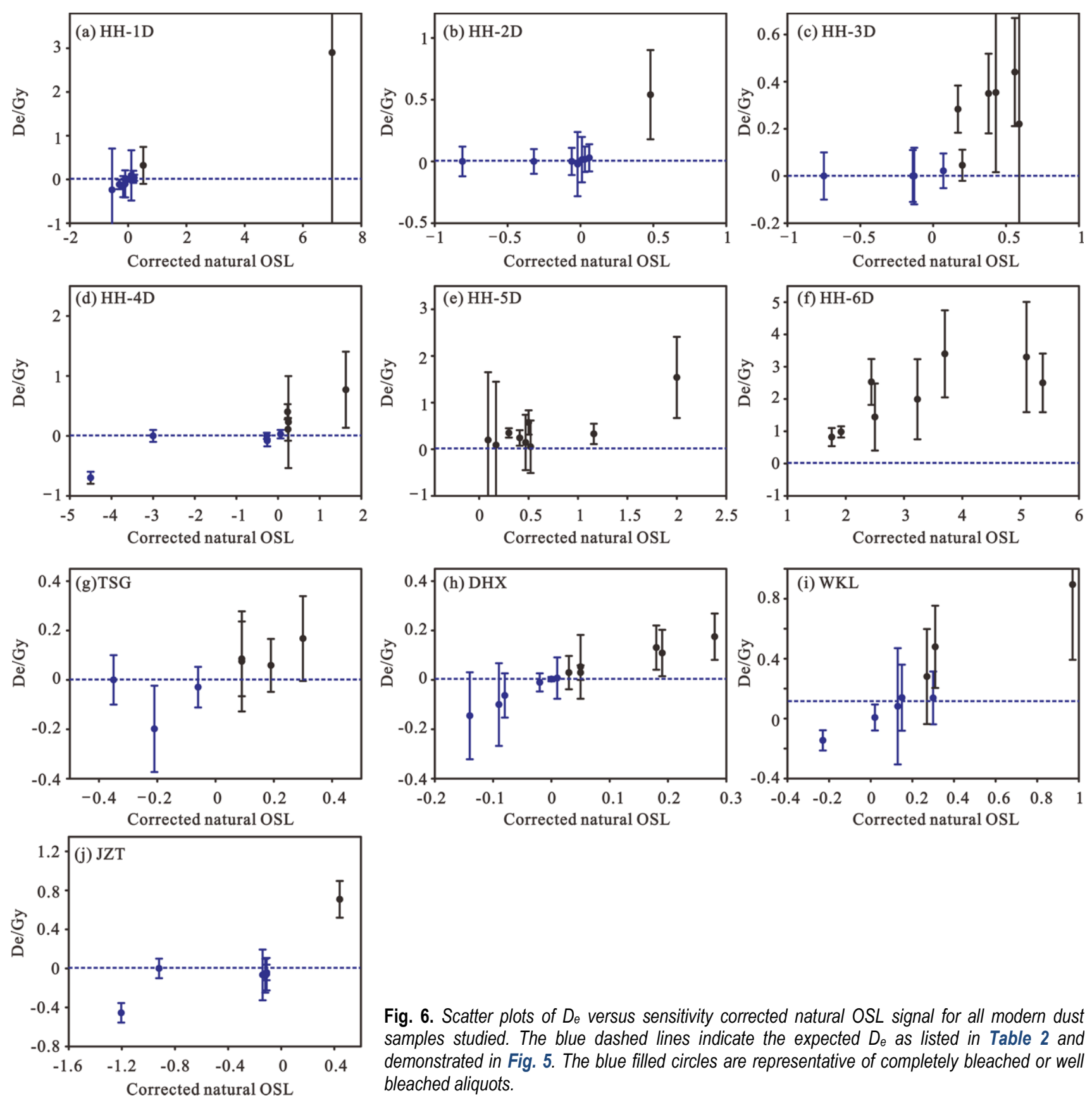

Fig. 6. Scatter plots of $D_{e}$ versus sensitivity corrected natural OSL signal for all modern dust samples studied. The blue dashed lines indicate the expected $D_{e}$ as listed in Table 2 and demonstrated in Fig. 5 . The blue filled circles are representative of completely bleached or well bleached aliquots.

5h). For other samples such as HH-5D and HH-6D, the $D_{e}$ distribution is relatively dispersed and no $D_{e}$ is smaller than the expected maximal $D_{e}$ (Fig. 5e and 5f). The uncertainties of measurement and instrument, however, sometimes can result in low precision of $D_{e}$ values. An alternative, plot of $D_{e}$ against uncertainties of measurement and instrument, is often used to exclude the effect of uncertainty of measurement and instrument on $\mathrm{D}_{\mathrm{e}}$ and thus $\mathrm{D}_{\mathrm{e}}$ distribution (Vandenberghe et al., 2007, 2009; Derese et al., 2009). To demonstrate the precision of each $D_{e}$ value and if larger $D_{e}$ is significantly different from a lower one, $\mathrm{D}_{\mathrm{e}}$ values are plotted against standard errors to top of each histogram in Fig. 5. The uncertainties of some larger $D_{e}$ values are smaller than those of the smaller $D_{e}$ values as inferred from samples HH-4D, HH-5D and JZT (Fig. 5d, 5e and 5j), indicating that the larger $D_{e}$ is not resulted from uncertainty of measurement and instrument at least in these samples. Therefore we conclude that the dispersed $\mathrm{D}_{\mathrm{e}}$ distribution likely supports poor bleaching.

\section{$D_{e}$ increases with natural OSL signal intensity}

Bleaching of luminescence signals can be evaluated in the scatter plot of $D_{e}$ versus sensitivity corrected natural OSL signal ( $\mathrm{Li}$ and Wintle, 1992). $\mathrm{D}_{\mathrm{e}}$ values of samples 
with different luminescence property should only cause the random spread of $D_{e}$, but $D_{e}$ will increase linearly with the increased corrected natural OSL signal for incompletely bleached samples (Clarke, 1996; Stokes et al., 2001; Li, 2001; Zhang et al., 2003). Only $\mathrm{D}_{\mathrm{e}}$ values larger than zero are discussed in the scatter plots because zero and negative $D_{e}$ values are representative of complete bleaching (Fig. 6h, blue filled circles). As illustrated in Fig. 6, the $D_{\mathrm{e}}$ values do not increase with the sensitivity corrected natural OSL signal (i.e., Fig. 6d, 6e), indicating that they were well bleached. For sample HH-1D, nearly all of its measured $\mathrm{D}_{\mathrm{e}} \mathrm{s}$ except one outlier are centralized and close to the expected $\mathrm{D}_{\mathrm{e}}$ without a clear increasing trend (Fig. 6a), suggesting that sample HH-1D were well bleached. Likewise, the $\mathrm{D}_{\mathrm{e}} \mathrm{s}$ (except one outlier) of sample HH-2D are independent of the sensitivity corrected natural OSL signal (Fig. 6b), indicating apparently this sample was also completely bleached. The samples JZT (except two outliers), TSG (except two outliers with large uncertainty) and DHX (except outliers with large uncertainty) are similar to HH-2D in the scatter plots (Fig. 6g, 6j and 6h). On the contrary, for sample HH-6D, the measured $D_{e} s$ increase apparently with the sensitivity corrected natural OSL signal (Fig. 6f). The $D_{e}$ values of other samples such as HH-4D and WKL obvious increase with sensitivity corrected natural OSL signals (Fig. 6d, 6i), indicating these samples potentially suffered incomplete bleaching before last deposition.

In summary, comparison of measured $\mathrm{D}_{\mathrm{e}}$ with the expected $D_{e}$, the $D_{e}$ values distributions in histograms and scatter plots of $\mathrm{D}_{\mathrm{e}}$ with sensitivity corrected natural OSL signal intensity consistently supports that some dust samples were still incompletely bleached or poorly bleached before burial although most dusts were well bleached. For instance, samples such as HH-1D and HH-2D were bleached completely bleached while samples including HH-5D and HH-6D were not bleached completely because nearly all their $D_{e}$ values of the latter are apparently larger than the expected control. For the rest samples, both negative and positive $D_{e}$ values are observed, suggesting that some grains are completely bleached or maybe have experienced reworking after deposition while others are not bleached completely before last deposition.

\section{DISCUSSIONS}

Both well bleached samples and poorly/incompletely bleached samples have been identified in modern dust samples. This observation stands in contrast to previous ideas that dust would experience complete bleaching before deposition. Unfortunately, we have little knowledge about the reasons that caused incomplete bleaching for the samples studied at present. Here, we discuss the potential reasons for poor bleaching with regard to source difference and sedimentation rates.

\section{Source difference is not the main reason}

It is indicated in previous publications that quartz from different sources behave differently in their response to irradiation (Jain et al., 2003; Zheng et al., 2009). And the TL and OSL signal obtained in response to a fixed dose related to the sources of the grains and their thermal histories (Chen et al., 2000; Li, 2001, 2002). By plotting the OSL signal versus $110^{\circ} \mathrm{C}$ TL signal in response to the test dose, Li et al. (2007) studied sample sources of different deserts in northern China and found that sensitivity of quartz will be a sensitive indicator for their sources. We tried to follow such an idea to test whether source differences can give a clue to the difference of bleaching characters of OSL signal and large scatter of equivalent doses for the studied samples or not. The test-dose $110^{\circ} \mathrm{C}$ TL was plotted against the test-dose OSL of each aliquot for all dust samples in Fig. 7. We used the same test dose for all dust samples and found big difference in test dose OSL signals. As illustrated in Fig. 7, all samples (except for sample DHX) including the completely bleached samples (e.g., HH-1D and HH-2D) and the incompletely bleached samples (e.g., HH-5D and HH-6D) fall into the same field characterized by low luminescence sensitivity (shaded area), suggesting that they have the same source, maybe local deserts. Another probable explanation for the result is that these sediments maybe come from fluvial grains, since most sites are located at the bank of the river. Some grains of sample DHX show a different source and mixture of aeolian and/or fluvial materials may be responsible for this difference. However, no matter where these dusts come from, source differences should not be the main reason for the difference in OSL bleaching for these dusts.

\section{Fast deposition might cause incomplete bleaching}

It is possible that in some circumstances aeolian transport of grains would provide only relatively short duration and/or limited spectrum (Bailey and Arnold, 2006). From the mode of deposition, fast deposition of near-source dust may be responsible for incomplete bleaching. For instance, dust from near source might have less chance and insufficient time to be completely bleached than those transported from distant source. In previous research abrupt changes in sedimentation rates between $0.05-3.45 \mathrm{~mm} / \mathrm{a}$ was found by using luminescence dating in the thick loess-soil profile in the Chinese Loess Plateau, which was interpreted as a result of change in sedimentation rates caused by near-source contribution (Jiang et al., 1998). This research indicated that high sedimentation rates might be a potential cause to difference in OSL signal bleaching. Considering that these modern dust samples are actually collected from the same area within $\sim 10 \mathrm{~km}$ (Fig. 1), the evidence as mentioned above supports that these aeolian sediments have the same source. Hence, we deduce that fast deposition caused by high sedimentation rates probably contributes 


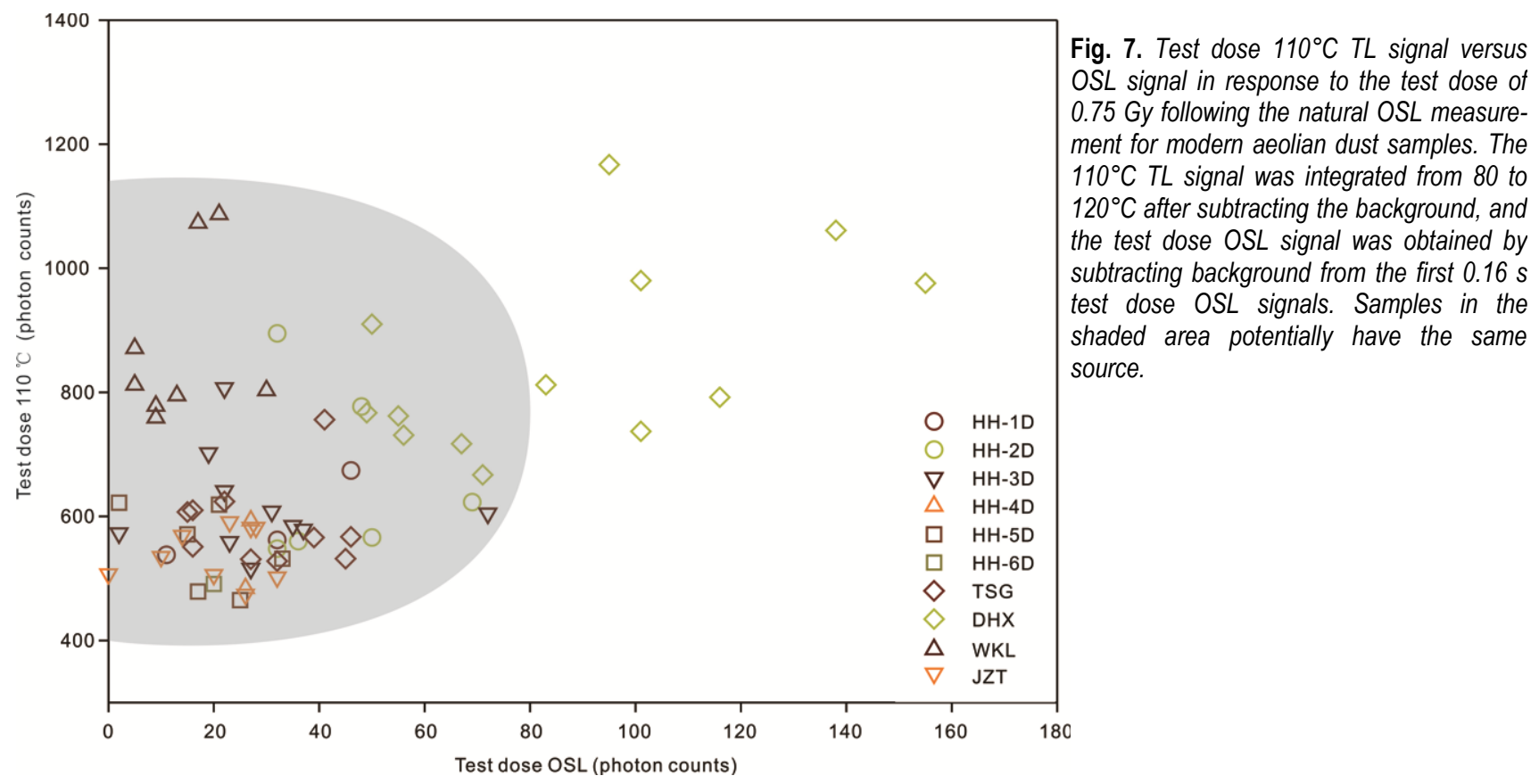

to the incomplete bleaching found in this study, which might be accompanied by heavy sand/dust storm, especially at night.

The incomplete bleaching might happen in two situations when heavy sand/dust storm occurs in northern China. Firstly, sand/dust storms is normally accompanied by heavy overcast. When transported during heavy overcast days and/or at night, dust was seldom exposed to sunlight to be bleached. And the sunlight attenuated substantially which lead to limited spectrum considering the ability of reflection, scattering and attenuation of heavy dust. Secondly, near-source dust might also be produced through erosion of sediments on Yellow River terraces when sand/dust storms happen along the Yellow River valley in our sampling area. The near-source dusts are hard to be bleached and deposited rapidly during short distance transportation.

\section{CONCLUSIONS}

OSL signals of quartz fractions from modern aeolian dust with known maximum age (about decades) were measured to investigate whether they were completely bleached or not before last deposition. Basing on $D_{e}$ distribution in histogram, scatter plots of $D_{e}$ with sensitivity corrected natural OSL signal intensity and comparison of measured $D_{e}$ with their expected $D_{e}$, we found that not all modern aeolian dust from western Chinese Loess Plateau experienced sufficient bleaching before deposition. For those poorly bleached samples, the OSL age was overestimated up to around $1 \mathrm{ka}$. We deduce that fast deposition of near source dust probably contributes to the poor bleaching identified in this study, which might be accom- panied by heavy sand/dust storms in northern China. Therefore caution should be given to OSL ages younger than $1 \mathrm{ka}$ in the western China close to deserts.

\section{ACKNOWLEDGEMENTS}

The authors thank Madam D.F. Mu for her contribution to parts of the laboratory work and Professor M.R. Qiang and associate Professor X.Z. Huang for their contributions to edit the former manuscript. The authors also appreciate X.L. Wang and an anonymous reviewer for their thorough reviews and many constructive comments on the manuscript. This study is supported by Chinese National Programs for Fundamental Research and Development (Project No.2010CB950202), National Natural Sciences Foundation of China (Projects No.41172163, 40972116), the Fundamental Research Funds for the Central Universities (No. lzujbky-2013-k17) and program for New Century Excellent Talents in University (No. NCET-12-0251).

\section{REFERENCES}

Alexanderson H and Murray AS, 2007. Was southern Sweden ice free at 19-25 ka, or were the post LGM glacial fluvial sediments incompletely bleached? Quaternary Geochronology 2(1-4): 229236, DOI 10.1016/j.quageo.2006.05.007.

Alexanderson H and Murray AS, 2012. Luminescence signals from modern sediments in a glaciated bay, NW Svalbard. Quaternary Geochronology 10: 250-256, DOI 10.1016/j.quageo.2012.01.001.

Armitage SJ and Bailey RM, 2005. The measured dependence of laboratory beta dose rates on sample grain size. Radiation Measurements 39(2): 123-127, DOI 10.1016/j.radmeas.2004.06.008.

Arnold LJ, Roberts RG, Galbraith RF and DeLong SB, 2009. A revised burial dose estimation procedure for optical dating of young and 
modern-age sediments. Quaternary Geochronology 4(4): 306-325, DOI 10.1016/j.quageo.2009.02.017.

Bailey RM and Arnold LJ, 2006. Statistical modeling of single grain quartz $\mathrm{D}_{\mathrm{e}}$ distributions and an assessment of procedure for estimating burial dose. Quaternary Science Reviews 25(19-20): 24752502, DOI 10.1016/j.quascirev.2005.09.012.

Bailey RM, Smith BW and Rhodes EJ, 1997. Partial bleaching and the decay form characteristics of quartz OSL. Radiation Measurements 27(2): 123-136, DOI 10.1016/S1350-4487(96)00157-6.

Ballarini M, Wallinga J, Wintle AG and Bos AJJ, 2007. A modified SAR protocol for optical dating of individual grains from young quartz samples. Radiation Measurements 42(3): 360-369, DOI 10.1016/j.radmeas.2006.12.016.

Banerjee D, Murray AS, Bøtter-Jensen L and Lang A, 2001. Equvalent dose estimation using a single aliquot of polymineral fine grains. Radiation Measurements 33(1): 73-94, DOI 10.1016/S13504487(00)00101-3.

Berger GW, Mulhern PJ and Huntley DJ, 1980. Isolation of silt-sized quartz from sediments. Ancient TL 11: 8-9.

Brill D, Klasen N, Bruckner H, Jankaew K, Scheffers A, Kelletat D and Scheffers S, 2012. OSL dating of tsunami deposits from Phra Thong Island, Thailand. Quaternary Geochronology 10: 224-229, DOI 10.1016/j.quageo.2012.02.016.

Bulur E, 1996. An alternative technique for optically stimulated luminescence (OSL) experiment. Radiation. Measurements 26(5): 701-709, DOI 10.1016/S1350-4487(97)82884-3.

Chen G, Li SH and Murray AS, 2000. Study of the $110^{\circ} \mathrm{C}$ TL peak sensitivity in optical dating of quartz. Radiation Measurements 32(5-6): 641-645, DOI 10.1016/S1350-4487(00)00129-3.

Clarke ML, 1996. IRSL dating of sands: bleaching characteristics at deposition inferred from the use of single aliquots. Radiation Measurements 26(4): 611-620, DOI 10.1016/13504487(96)00004-2.

Colls AE, Stokes S, Blum MD and Straffin E, 2001. Age limits on the Late Quaternary evolutions of the upper Loire River. Quaternary Science Reviews 20(5-9): 743-750, DOI 10.1016/S02773791(00)00048-2.

Costas I, Reimann T, Tsukamoto S, Ludwig J, Lindhorst S, Frechen M, Hass HC and Betzler C, 2012. Comparison of OSL ages from young dune sediments with a high-resolution independent age model. Quaternary Geochronology 10: 16-23, DOI 10.1016/j.quageo.2012.03.007.

Cunningham A and Wallinga J, 2009. Optically stimulated luminescence dating of young quartz using the fast component. Radiation Measurements 44(5-6): 10.1016/j.radmeas.2009.02.014

Cunningham A and Wallinga $J, 2010$. Selection of integration time intervals for quartz OSL decay curves. Quaternary Geochronology 5(6): 657-666, DOI 10.1016/j.quageo.2010.08.004.

Derese C, Vandenberghe D, Paulissen E and Van den haute P, 2009. Revisiting a type locality for Late Glacial aeolian sand deposition in NW Europe: Optical dating of the dune complex at Opgrimbie (NE Belgium). Geomorphology 109(1-2): 27-35, DOI 10.1016/j.geomorph.2008.08.022.

Duller GAT, 2008. Single-grain optical dating of Quaternary sediments: why aliquots size matters in luminescence dating. Boreas 37(4): 589-612, DOI 10.1111/j.1502-3885.2008.00051.x.

Fiebig M and Preusser F, 2007. Investigating the amount of zeroing in modern sediments of River Danube, Austria. Quaternary Geochronology 2(1-4): 143-149, DOI 10.1016/j.quageo.2006.09.001.

Forman S, 1991. Late Pleistocene chronology of loess deposition near Luochuan, China. Quaternary Research 36(1): 19-28, DOI 10.1016/0033-5894(91)90014-V

Fuchs M and Owen LA, 2008. Luminescence dating of glacial and associated sediments: review, recommendations and future directions. Boreas 37(4): 636-659, DOI 10.1111/j.15023885.2008.00052.x.

Galbraith RF and Roberts RG, 2012. Statistical aspects of equivalent dose and error calculation and display in OSL dating: An overview and some recommendations. Quaternary Geochronology 11: 1-27, DOI 10.1016/j.quageo.2012.04.020.
Gemmell AMD, Murray AS and Connell ER, 2007. Devensian glacial events in Buchan (NE Scotland): A progress report on new OSL dates and their implications. Quaternary Geochronology 2(1-4): 237-242, DOI 10.1016/j.quageo.2006.05.016.

Goble RJ, Mason JA, Loope DB and Swinehart JB, 2004. Optical and radiocarbon ages of stacked paleosols and dune sands in the $\mathrm{Ne}$ braska Sand Hills, USA. Quaternary Science Reviews 23(9-10): 1173-1182, DOI 10.1016/j.quascirev.2003.09.009.

Hu G, Zhang JF, Qiu WL and Zhou LP, 2010. Residual OSL signals in modern fluvial sediments from the Yellow River (HuangHe) and the implications for dating young sediments. Quaternary Geochronology 5(2-3): 187-193, DOI 10.1016/j.quageo.2009.05.003.

Huntley DJ and Clague JJ, 1996. Optical Dating of Tsunami-Laid Sands. Quaternary Research 46(2): 127-140, DOI 10.1006/qres.1996.0053.

Jain M, Murray AS and Bøtter-Jensen L, 2003. Characterisation of bluelight stimulated luminescence components in different quartz samples: implications for dose measurement. Radiation Measurements 37(4-5): 441-449, DOI 10.1016/S1350-4487(03)00052-0.

Jain M, Murray AS and Bøtter-Jensen L, 2004. Optically stimulated luminescence dating: how significant is incomplete light exposure in fluvial environments? Quaternaire 15(1-2): 143-157, DOI 10.3406/quate.2004.1762.

Jiang FC, Wu XH, Sun DH, Xiao HG, Wang SM, An ZS, Tian GQ, Liu K, Yin WD and Xue B, 1998. On mangshan loess stratigraphy in China Central Plains. Journal of Geomechanics 4(4): 12-18 (in Chinese).

Jiang HC, Wang P, Thompson J, Ding ZL and Lu YC, 2009. Last glacial climate instability documented by coarse-grained sediments within the loess sequence, at Fanjiaping, Lanzhou, China. Ouaternary Research 72(1): 91-102, DOI 10.1016/j.yqres.2009.04.005.

Lai ZP, Wintle AG and Thomas DSG, 2007. Rates of dust deposition between $50 \mathrm{ka}$ and $20 \mathrm{ka}$ revealed by OSL dating at Yuanbao on the Chinese Loess Plateau. Palaeogeography, Paleoclimatology, Palaeoecology 248(3-4): 431-439,

DOI 10.1016/j.palaeo.2006.12.013.

Li SH, 2001. Identification of well-bleached grains in the optical dating of quartz. Quaternary Science Reviews 20(12): 1365-1370, DOI 10.1016/S0277-3791(00)00156-6.

Li SH, 2002. Luminescence sensitivity changes of quartz by bleaching, annealing and UV exposure. Radiation Effects and Defects in Solids 157(3): 357-364, DOI 10.1080/10420150212998.

Li SH, Chen YY, Li B, Sun JM and Yang LR, 2007. OSL dating of sediments from deserts in northern China. Quaternary Geochronology 2(1-4): 23-28, DOI 10.1016/j.quageo.2006.05.034.

Li SH and Wintle AG, 1992. Luminescence sensitivity change due to bleaching of sediments. Nuclear Tracks Radiations Measurements 20(4): 567-573, DOI 10.1016/1359-0189(92)90006-H.

$\mathrm{Lu}$ YC, Wang XL and Wintle AG, 2007. A new OSL chronology for dust accumulation in the last 130, $000 \mathrm{yr}$ for the Chinese Loess Plateau. Quaternary Research 67(1): 152-160, DOI 10.1016/j.yqres.2006.08.003.

$\mathrm{Lu}$ YC, Zhang JZ and Xie J, 1988. Thermoluminescence dating of loess and palaeosols from Lantian section, Shaanxi Province, China. Quaternary Science Reviews 7(3-4): 245-250, DOI 10.1016/02773791(88)90011-X.

Madsen AT and Murray AS, 2009. Optically stimulated luminescence dating of young sediments: A review. Geomorphology 109(1-2): 316, DOI 10.1016/j.geomorph.2008.08.020.

Murray AS and Wintle AG, 2003. The single aliquot regenerative dose protocol: potential for improvements in reliability. Radiation Measurements 37(4-5): 377-381, DOI 10.1016/S13504487(03)00053-2.

Murray AS, Thomsen KJ, Masuda N, Buylaert JP and Jain M, 2012. Identifying well-bleached quartz using the different bleaching rates of quartz and feldspar luminescence signals. Radiation Measurements 47(9): 688-695, DOI 10.1016/j.radmeas.2012.05.006.

Olley JM, Caitcheon GG and Murray AS, 1998. The distribution of apparent dose as determined by optically stimulated luminescence in small aliquots of fluvial quartz: implications for dating young 
sediments. Quaternary Geochronology 17(11): 1033-1040, DOI 10.1016/S0277-3791(97)00090-5.

Olley JM, Caitcheon GG and Roberts RG, 1999. The origin of dose distributions in fluvial sediments, and the prospect of dating single grains from fluvial deposits using optically stimulated luminescence. Radiation Measurements 30(2): 207-217, DOI 10.1016/S1350-4487(99)00040-2.

Pietsch TJ, 2009. Optically stimulated luminescence dating of young ( $<500$ year old) sediments: Testing estimates of burial dose. Quaternary Geochronology 4(5): 406-422, DOI 10.1016/j.quageo.2009.05.013.

Qian ZA, Cai Y, Liu JT, Li DL, Liu ZM and Song MH, 2004. Some Advances in Dust Storm Researches in Northern China. Journal of Arid Land and Resources and Environment 18(1): 1-8 (in Chinese).

Roberts HM and Wintle AG, 2001. Equvalent dose determinations for polymineralic fine-grains using the SAR protocol: application to a Holocene sequence of the Chinese Loess Plateau. Quaternary Science Reviews 20(5-9): 859-863, DOI 10.1016/S02773791(00)00051-2.

Roberts HM, 2008. The development and application of luminescence dating to loess deposits: a perspective on the past, present and future. Boreas 37(4): 483-507, DOI 10.1111/j.15023885.2008.00057.x.

Shen ZX and Mauz B, 2012. Optical dating of young deltaic deposits on a decadal time scale. Quaternary Geochronology 10: 110-116, DOI 10.1016/j.quageo.2012.01.014.

Singarayer JS and Bailey RM, 2004. Component-resolved bleaching spectra of quartz optically stimulated luminescence: preliminary results and implications for dating. Radiation Measurements 38(1): 111-118, DOI 10.1016/S1350-4487(03)00250-6.

Singarayer JS, Bailey RM, Ward S and Stokes S, 2005. Assessing the completeness of optical resetting of quartz OSL in the natural environment. Radiation Measurements 40(1): 13-25, DOI 10.1016/j.radmeas.2005.02.005.

Stokes S, Bailey RM, Fedoroff N and O'Marah KE, 2004. Optical dating of aeolian dynamism on the West African Sahelian margin. Geomorphology $\quad 59(1): \quad 281-291, \quad$ DOI 10.1016/j.geomorph.2003.07.021.

Stokes S, Bray HE and Blum MD, 2001. Optical resetting in large drainage basins: tests of zeroing assumptions using single-aliquot procedures. Quaternary Science Reviews 20(5-9): 879-885, DOI 10.1016/S0277-3791(00)00045-7.

Sun DH, Lu HY, David R, Sun YB and Wu SG, 2000. Bimodal grainsize distribution of Chinese Loess and its paleoclimate implications. CATENA 55(3): 325-340, DOI 10.1016/S03418162(03)00109-7.

Thomsen K, Bøtter-Jensen L, Jain M, Denby PM and Murray AS, 2008. Recnet instrumental developments for trapped electron dosimetry. Radiation Measurement 43(2-6): 414-421, DOI 10.1016/j.radmeas.2008.01.003.

Tooth S, Rodnight H, Duller GAT, McCarthy TS, Marren PM and Brandt D, 2007. Chronology and controls of avulsion along a mixed bedrock-alluvial river. Geological Society of America Bulletin 119(3-4): 452-461, DOI 10.1130/B26032.1.

Vandenberghe D, Derese C and Houbrechts G, 2007. Residual doses in recent alluvial sediments from the Ardenne (S Belgium). Geochronometria 28: 1-8, DOI 10.2478/v10003-007-0024-z.

Vandenberghe D, Vanneste K, Verbeeck K, Paulissen E, Buylaert JP, De Corte F and Van den haute P, 2009. Late Weichselian and Holocene earthquake events along the Gellen fault in NE Belgium: OSL age constraints. Quaternary International 199(1-2): 56-74, DOI 10.1016/j.quaint.2007.11.017.

Wallinga J, Bos AJJ and Duller GAT, 2008. On the separation of quartz OSL signal components using different stimulation modes. Radiation Measurements 43(2-6): 742-747, $\quad$ DOI 10.1016/j.radmeas.2008.01.013.

Wintle AG and Murray AS, 2006. A review of quartz optically stimulated luminescence characteristics and their relevance in singlealiquot regeneration dating protocols. Radiation Measurements 41(4): 369-391, DOI 10.1016/j.radmeas.2005.11.001.

Zhang JF, Zhou LP and Yue SY, 2003. Dating fluvial sediments by optical stimulated luminescence: selection of equivalent doses for age calculation. Quaternary Science Reviews 22(10-13): 11231129, DOI 10.1016/S0277-3791(03)00054-4.

Zhang XY, 2007. Review on source and transport of loess materials on the Chinese Loess Plateau. Quaternary Science 27(2): 181-186 (in Chinese).

Zheng CX, ZhouLP and Qin JT, 2009. Difference in luminescence sensitivity of coarse-grained quartz from deserts of northern China. Radiation Measurements 44(5-6): 534-537, DOI 10.1016/j.radmeas.2009.02.013. 